\title{
Changes in dominance among species in aquatic hyphomycete assemblages do not affect litter decomposition rates
}

\author{
Verónica Ferreira $^{1, *}$, Eric Chauvet ${ }^{2,3}$ \\ ${ }^{1}$ IMAR-CMA, Department of Life Sciences, University of Coimbra, 3001-401 Coimbra, Portugal \\ ${ }^{2}$ Université de Toulouse, UPS, INPT, and ${ }^{3}$ CNRS, EcoLab (Laboratoire Ecologie Fonctionnelle et Environnement), \\ 31062 Toulouse, France
}

\begin{abstract}
Fresh waters are threatened worldwide by water pollution and extraction, changes in riparian vegetation and global warming. Changes in community dominance are expected as an early outcome of anthropogenic stresses, later followed by a reduction in species number and changes in species identity, which might impair ecosystem processes. Here, we addressed the effect of changes in dominance among species in fungal assemblages on the decomposition of alder leaves and associated fungal activity. In laboratory microcosms, we inoculated alder leaf discs with 2 fungal assemblages, each composed of 3 species known to dominate communities during early decomposition (early assemblage) and late decomposition (late assemblage). For each assemblage type, the identity of the dominant species was tentatively manipulated by inoculating the microcosms with distinct proportions of conidia in 4 inocula: an even inoculum and 3 uneven inocula (each dominated by a different species). Over the incubation time, all early assemblages became dominated by the same aquatic hyphomycete species, while manipulation of the number of conidia in the inocula successfully determined the dominant species in late assemblages. Total conidial production and respiration rates differed among early assemblages, but no differences were found in litter decomposition and associated fungal variables among late assemblages. The absence of a relationship between community dominance/identity of the dominant species and community performance/litter mass loss suggests that assemblages, even those composed of a low number of species, have the capacity to buffer changes in processes due to changes in species dominance.
\end{abstract}

Resale or republication not permitted without written consent of the publisher

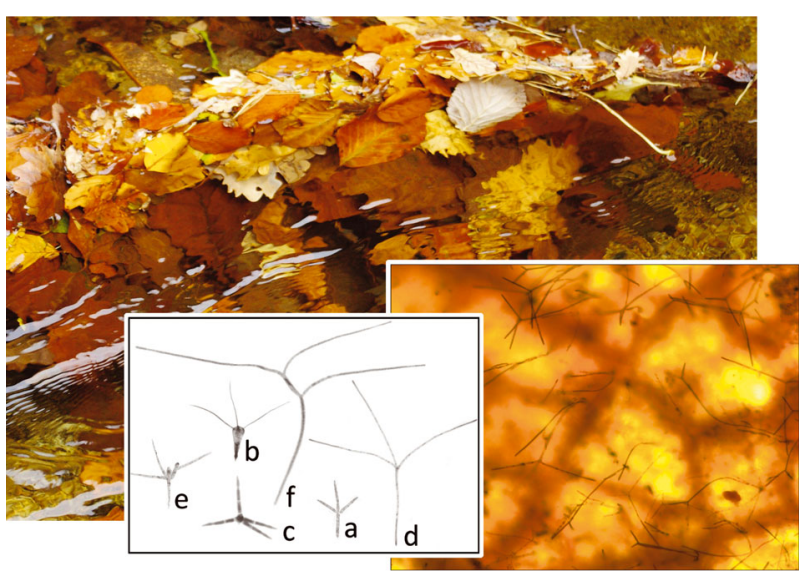

Top: Autumnal leaves shed in a temperate stream. Bottom (right): Mycelium, conidiophores and conidia of aquatic hyphomycetes (mostly of Tetrachaetum elegans) developed on a leaf blade. Bottom (left): Conidia from the species used: (a) Articulospora tetracladia, (b) Clavariopsis aquatica, (c) Lemonniera terrestris, (d) T. elegans, (e) Tetracladium marchalianum, (f) Tricladium chaetocladium

Photos: E. Chauvet and V. Ferreira

KEY WORDS: Dominance - Evenness - Species identity $\cdot$ Litter decomposition · Biodiversity $\cdot$ Aquatic fungi $\cdot$ Fungal activity.

\section{INTRODUCTION}

Fresh waters are presently among the most endangered ecosystems in the world, and this situation is expected to deteriorate in the near future, in part as a result of increases in demands for fresh water and in loads of nutrients and pollutants into aquatic systems from a growing human population 
(MEA 2005). Small forest streams are also highly vulnerable to global warming because most of their biota have relatively low upper thermal tolerance limits (deKozlowski \& Bunting 1981, Eaton \& Scheller 1996) and will lack thermal refugia if they are already at their high latitude or highland limit. Also, the heterotrophic nature of these small streams and their strong interaction with the terrestrial surroundings (Vannote et al. 1980, Mulholland et al. 2001) make them most sensitive to changes in the riparian vegetation, which can result from invasion by exotic species, conversion of diverse deciduous forests into tree monocultures or agricultural fields, vegetation removal by forestry practices or urban development (Chadwick et al. 2006, Ferreira et al. 2006b, Lecerf et al. 2007, Castela et al. 2008). All these threats have been shown to induce changes in the structure of aquatic communities (Bärlocher \& Graça 2002, Pascoal et al. 2005, Ferreira et al. 2006b, Castela et al. 2008, Dang et al. 2009), which might have profound consequences for the maintenance of ecosystem processes.

In small shaded streams, where primary production is limited by reduced light penetration, food webs derive most of their energy and carbon from allochthonous organic matter (Fisher \& Likens 1973, Vannote et al. 1980). The decomposition of this organic material is carried out by an array of organisms, and aquatic hyphomycetes are key actors in this process (Hieber \& Gessner 2002, Gulis \& Suberkropp 2003, Pascoal \& Cássio 2004). These fungi cause litter mass loss directly, by mineralizing it, converting it into biomass and releasing fine particulate organic matter through enzymatic maceration of litter, and indirectly by increasing litter palatability towards detritivores (Suberkropp \& Klug 1980, Bärlocher 1985, Hieber \& Gessner 2002, Gulis \& Suberkropp 2003, Chung \& Suberkropp 2009). Thus, changes in the community composition of these microorganisms have the potential to affect aquatic food webs and ecosystem functioning.

Early studies have shown that aquatic hyphomycete species differ in terms of degradative capabilities when they are inoculated individually on leaf litter (Suberkropp et al. 1983, Suberkropp \& Arsuffi 1984, Butler \& Suberkropp 1986), which would indicate that communities dominated by such species would decompose leaf litter at different rates. The importance of dominant species in driving ecosystem processes has been demonstrated previously (Hector et al. 2000, Smith \& Knapp 2003, Dangles \& Malmqvist 2004, Ellison et al. 2005, Hillebrand et al. 2008). However, leaf litter incubated in streams with dis- tinct aquatic hyphomycete communities (different species richness and identity) decomposes at similar rates, which suggests a certain level of functional redundancy among communities (Bärlocher \& Graça 2002, Pascoal et al. 2005, Ferreira et al. 2006b, but see Baudoin et al. 2008). Though different communities might decompose litter at similar rates, this probably results from the interaction between species number, identity (i.e. individual degradative capabilities that may compensate each other in species assemblages) and environmental variables. Conversely, some indication for non-redundancy among aquatic hyphomycete communities comes from studies where the effect of species richness on litter decomposition and fungal variables was examined in several distinct communities within each diversity level (Bärlocher \& Corkum 2003, Dang et al. 2005, Duarte et al. 2006). Despite the conflicting results regarding the effect of species richness among the latter studies, a closer look at the (sometimes high) variation of effect size among communities within a given diversity level indicates the importance of species composition. Nevertheless, the effects of changes in fungal community structure, due solely to changes in dominance among species, on litter decomposition have not been assessed, despite these being expected to occur before there is a reduction in species number and changes in species identity due to anthropogenic stresses (Ellison et al. 2005, Hillebrand et al. 2008). In fact, the relationship between species evenness and ecosystem processes has been addressed only recently (Wilsey \& Potvin 2000, Dangles \& Malmqvist 2004, McKie et al. 2008, Gonçalves \& Canhoto 2009, Swan et al. 2009, Ward et al. 2010), and its relevance for microbial communities has not yet been examined.

In this experiment, we assessed whether changes in the identity of the dominant species in aquatic hyphomycete assemblages would affect decomposition rates of alder leaves and associated fungal activity. The identity of the dominant species was manipulated within each of 2 fungal communities known to colonize litter at different decomposition stages, to overcome the issue of assembling species randomly without taking into account natural co-occurrence. Given that (1) our assemblages include aquatic hyphomycete species that differ in their degradative capabilities (Zemek et al. 1985) and (2) dominant species play an important role in driving ecosystem processes, differences in rates of leaf processing by fungal assemblages differing in their dominant species are anticipated. If these changes happen, then impacts on litter processing in fresh waters might 
occur well before there is species loss due to anthropogenic activities.

\section{MATERIALS AND METHODS}

\section{Microcosms}

The effect of the dominant fungal species identity on the decomposition of alder (Alnus glutinosa [L.] Gaertner) leaf discs was assessed in laboratory microcosms designed to simulate stream conditions (Suberkropp 1991). Each microcosm consisted of a $50 \mathrm{ml}$ glass chamber aerated from the bottom by a continuous air flow (80 to $100 \mathrm{ml} \mathrm{min}^{-1}$ ), which created turbulence and kept the leaf discs in permanent agitation. A tap at the bottom allowed for the aseptic drainage of the chamber and recovery of the conidial suspension (see 'Fungal sporulation' section). Microcosms were filled with a nutrient solution $(75.5 \mathrm{mg}$ $\mathrm{CaCl}_{2}, 10 \mathrm{mg} \mathrm{MgSO}_{4} \cdot 7 \mathrm{H}_{2} \mathrm{O}, 0.5 \mathrm{~g}$ 3-morpholinopropanesulfonic acid, $5.5 \mathrm{mg} \mathrm{K}_{2} \mathrm{HPO}_{4}$ and $100 \mathrm{mg}$ $\mathrm{KNO}_{3}$ per 1 of sterile distilled water) and incubated in the dark at $15^{\circ} \mathrm{C}$, for the duration of the experiment. Fresh medium $(40 \mathrm{ml})$ was added to microcosms through the open top, which was otherwise closed with a glass cap.

\section{Leaf discs}

Alder leaves collected just after abscission on 30 December 2006 at Gibel (southwestern France; $43^{\circ} 17^{\prime} 35^{\prime \prime} \mathrm{N}, 1^{\circ} 40^{\prime} 51^{\prime \prime} \mathrm{E}$ ) and dried at room temperature were moistened with distilled water and left to rehydrate overnight. Leaf discs were cut out with a $12 \mathrm{~mm}$ diameter cork borer and oven dried $\left(105^{\circ} \mathrm{C}\right)$ prior to use. Batches of 20 leaf discs were frozen at $-20^{\circ} \mathrm{C}$, lyophilized $(20 \mathrm{~h})$, weighed $( \pm 0.1 \mathrm{mg})$ to determine initial dry mass (DM), placed inside glass tubes with $10 \mathrm{ml}$ of distilled water and autoclaved $\left(20 \mathrm{~min}\right.$ at $\left.121^{\circ} \mathrm{C}\right)$. Six batches of 20 leaf discs were given the same treatment and were used to determine the correction factor for mass loss due to leaching during sterilization.

\section{Fungal assemblages}

Six species of aquatic hyphomycetes frequently reported to be dominant in leaf litter in streams were used in this experiment: Articulospora tetracladia Ingold (ARTE), Clavariopsis aquatica de Wildeman
(CLAQ), Lemonniera terrestris Tubaki (LETE), Tetrachaetum elegans Ingold (THEL), Tetracladium marchalianum Ingold (TEMA) and Tricladium chaetocladium Ingold (TRCH) (Gessner et al. 1993, Suberkropp 2001, Ferreira et al. 2006b). Each fungal species was isolated from a single conidia trapped in naturally occurring foam or released from leaf-litter accumulations in one stream. Several streams in southern France with similar environmental characteristics were used for the collection of all species. Growing colonies were kept at room temperature, in $9 \mathrm{~cm}$ diameter Petri dishes with $\sim 10 \mathrm{ml}$ of sterile growth medium ( $2 \%$ malt and $2 \%$ agar), until they were used to induce conidial production. Conidial suspensions $(<24 \mathrm{~h}$ old $)$ were produced at $15^{\circ} \mathrm{C}$, by agitation of agar plugs taken from the leading edge of 7 to $14 \mathrm{~d}$ old colonies in $25 \mathrm{ml}$ of nutrient solution as before. A known amount of each conidial suspension was filtered (Millipore SMWP, pore size $5 \mu \mathrm{m}$, Millipore), and the filters were scanned under a compound microscope at a magnification of $320 \times$. The number of trapped conidia was used to determine the conidial density of the suspensions and the volume of each suspension needed to inoculate the microcosms; when necessary, several conidial suspensions from the same fungal strain were joined to produce enough conidia.

\section{Experimental setup}

Half of the microcosms were inoculated with an assemblage composed of early colonizer species (LETE, THEL and TRCH), while the other half were inoculated with an assemblage composed of late colonizer species (ARTE, CLAQ and TEMA) (Gessner et al. 1993, Nikolcheva et al. 2003). For each assemblage type (early and late), there were 4 dominance treatments: (1) an even treatment, in which microcosms were inoculated with an even number of conidia from each species (33.3\% of each species), and (2-4) uneven treatments with (2) Species 1, (3) Species 2 or (4) Species 3 dominant, with that species representing $60 \%$ of total number of conidia inoculated and the other 2 species $20 \%$ each. The dominance of a given species was thus favored by increasing its representation in the initial conidial inoculum. A total of 5000 conidia were inoculated in each microcosm, with each treatment being applied to 3 microcosms. While aquatic hyphomycete assemblages composed of only 3 species may be considered unrealistic (Chamier et al. 1984), the use of only 3 species is justified by our interest in assessing the 
importance of the dominant species identity on the decomposition process; this is also supported by common reports on natural assemblages, where up to 3 species compose $>70 \%$ of the fungal community on submerged substrates (Gessner et al. 1993, Suberkropp \& Chauvet 1995, Gessner et al. 1998, Nikolcheva et al. 2003, Nikolcheva \& Bärlocher 2005, Ferreira et al. 2006a,b).

Sterilized microcosms (30 min at $121^{\circ} \mathrm{C}$ ) were filled with $40 \mathrm{ml}$ of the nutrient solution, received the corresponding leaf discs $(0.0954 \pm 0.0011 \mathrm{~g} \mathrm{DM})$ and were aerated for $24 \mathrm{~h}$. The nutrient solution was changed, and the microcosms were inoculated with conidial suspensions. For the first $2 \mathrm{~h}$, the microcosms were aerated for periods of 20 min interspaced with periods of $20 \mathrm{~min}$ in which the conidia were allowed to settle to facilitate conidial attachment to the litter. After this, microcosms were aerated continuously until the end of the experiment. The nutrient solution was replaced after $24 \mathrm{~h}$ and then every $3 \mathrm{~d}$ for the duration of the experiment (28 d). All manipulations of microcosms took place in a laminar flow cabinet.

\section{Fungal sporulation}

From Day 10, at each of the 7 times that the nutrient solution was removed, the conidial suspensions from all microcosms were poured into $50 \mathrm{ml}$ centrifuge tubes, the sample volume was adjusted to $42 \mathrm{ml}$ with distilled water, and the samples were preserved with $3 \mathrm{ml}$ of $35 \%$ formalin. When preparing filters for conidial counting and identification, $150 \mu \mathrm{l}$ Triton X-100 $(0.5 \%)$ were added to the suspension, mixed with a magnetic stirring bar, to ensure a uniform distribution of conidia, and an aliquot of the suspension was filtered (Millipore SMWP, pore size $5 \mu \mathrm{m}$, Millipore). Filters were stained with $0.05 \%$ Trypan blue in $60 \%$ lactic acid, and spores were identified and counted under a compound microscope at a magnification of $320 \times$ (Graça et al. 2005). The total conidial mass at each sampling date was calculated by multiplying the number of conidia from each species by the average mass of individual conidia obtained from the literature (Chauvet \& Suberkropp 1998) or calculated from biovolume data (Bärlocher \& Schweizer 1983). Cumulative conidial production over time was calculated by summing up the numbers or mass of conidia produced at the current and preceding sampling dates. Results were expressed as number of conidia microcosm $^{-1}$ and as mg conidia microcosm ${ }^{-1}$. For the last sampling date, results were also expressed as number of conidia $\mathrm{mg}^{-1}$ leaf $\mathrm{DM} \mathrm{d}^{-1}$.

\section{Fungal respiration}

At the end of the experiment, leaf discs were collected, and a subset of 5 discs from each microcosm were used to determine fungal oxygen consumption rates using a closed 6-channel dissolved oxygen measuring system (Strathkelvin 928 System) connected to a computer. The oxygen electrodes were calibrated against a freshly prepared $4 \%$ sodium sulfite solution $\left(0 \% \mathrm{O}_{2}\right)$ and a $100 \% \mathrm{O}_{2}$ saturated nutrient solution at $15^{\circ} \mathrm{C}$. Leaf discs were incubated in $3 \mathrm{ml}$ chambers filled with a sterile $100 \% \mathrm{O}_{2}$ saturated nutrient solution, stirred with a magnetic stirring bar and kept at $15^{\circ} \mathrm{C}$ by circulation of water originating from a temperature-controlled water bath. Additional chambers without leaf discs were used as controls. After the $1 \mathrm{~h}$ trial, leaf discs were enclosed in small sterile zip lock bags and promptly frozen at $-20^{\circ} \mathrm{C}$ for later DM determination and ergosterol extraction (see below). Oxygen consumption rates were determined by the difference in the $\mathrm{O}_{2}$ concentration in the sample and the control over a 20 min interval during which $\mathrm{O}_{2}$ consumption over time was linear, corrected for the chamber's volume, time and disc mass. Results were expressed as $\mathrm{mg} \mathrm{O}_{2} \mathrm{~g}^{-1}$ leaf $\mathrm{DM} \mathrm{h}^{-1}$.

\section{Leaf mass loss and mycelial biomass}

The remaining 15 leaf discs from each microcosm were enclosed in small sterile zip lock bags and promptly frozen at $-20^{\circ} \mathrm{C}$. All 20 leaf discs from each microcosm were combined, lyophilized, promptly weighed $( \pm 0.1 \mathrm{mg})$ to quantify the remaining DM and used for ergosterol extraction as a surrogate for mycelial biomass (Gessner \& Chauvet 1993, Graça et al. 2005). Lipid extraction and saponification were carried out in $5 \mathrm{ml} \mathrm{KOH} / \mathrm{methanol}\left(8 \mathrm{~g} \mathrm{l}^{-1}\right)$ at $80^{\circ} \mathrm{C}$ for $30 \mathrm{~min}$. The extract was then purified by solid phase extraction (Waters Oasis ${ }^{\circledR}$ HLB 3cc cartridges, Waters) (Graça et al. 2005) and quantified using highperformance liquid chromatography (HPLC 360, 422 and 432, Kontron) by measuring absorbance at $282 \mathrm{~nm}$. The HPLC detector was equipped with a FLT $0.5 \mu \mathrm{m}$ A-316 precolumn (Upchurch Scientific) and a LispRP 18-5 $250 \times 4.6 \mathrm{~mm}$ column (Thermo-Hypersil Keystone) maintained at $33^{\circ} \mathrm{C}$. The mobile phase was $100 \%$ methanol, and the flow rate was set to $1.4 \mathrm{ml}$ $\min ^{-1}$. Ergosterol was converted into mycelial biomass either using specific conversion factors $(4.2 \mu \mathrm{g}$ ergosterol $\mathrm{mg}^{-1}$ mycelium biomass for ARTE, 4.6 for CLAQ, 2.4 for LETE, 4.6 for TEMA and 4.7 for THEL) or the overall conversion factor $(5.5 \mu \mathrm{g}$ ergosterol 
$\mathrm{mg}^{-1}$ mycelium biomass for $\mathrm{TRCH}$; no specific conversion factor available) (Gessner \& Chauvet 1993), applied to the relative contribution of each species to total ergosterol mass based on specific contribution to total conidial production. Results were expressed as mg of mycelial biomass $\mathrm{g}^{-1}$ of leaf DM.

\section{Data treatment}

Within each dominance treatment, specific relative conidial numbers and mass observed until Day 28 were compared with those expected based on their initial relative contributions in the inoculum, using $\chi^{2}$ tests (Zar 1996). Within each assemblage type, total specific conidial productions (numbers and mass until Day 28) were compared within and among dominance treatments using 2-way ANOVAs (with dominance treatment and sporulating species as categorical factors) (Zar 1996). The relationships between specific relative and absolute conidial production across dominance treatments and initial relative and absolute abundance in the inocula, respectively, were assessed using linear regressions. The BergerParker dominance index, determined as the conidial production of the dominant species divided by the total conidial production, was used as a simple measure of the dominance of the most abundant species in each treatment (Berger \& Parker 1970). The relationships between the dominance index and fungal variables were assessed using Pearson correlations. The total conidial production, sporulation rate (log-transformed), mycelial biomass (log-transformed), respiration rate and percentage of leaf mass remaining at the end of the experiment were compared among dominance treatments within each assemblage type using nested ANOVA (identity of dominant species nested within dominance treatments) (Zar 1996). Tukey's honestly significant difference test was used for post-hoc multiple comparisons; when Tukey's test was insensitive to differences among treatments, Fisher's least significant difference test was used instead. All analyses were performed with STATISTICA 6 software (StatSoft).

\section{RESULTS}

\section{Early assemblages}

Manipulation of the number of conidia inoculated into the microcosms did not determine the specific relative abundances in early assemblages $\left(\chi^{2}\right.$ tests, Fig. 1). Early assemblages tended to be dominated by THEL (50 022 conidia microcosm ${ }^{-1}$ in the LETE treatment to 350876 conidia microcosm $^{-1}$ in the THEL treatment; Berger-Parker dominance index: 0.65 to 0.86), irrespective of the relative abundance of THEL conidia inoculated into the microcosms (Fig. 1); however, THEL conidial production across treatments

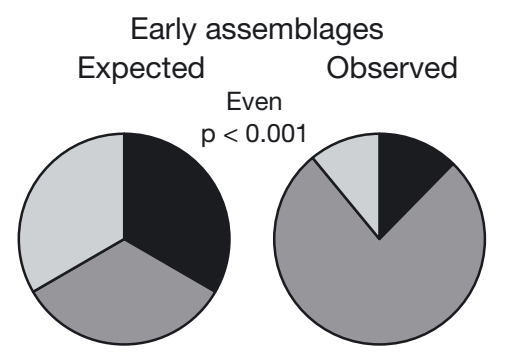

LETE

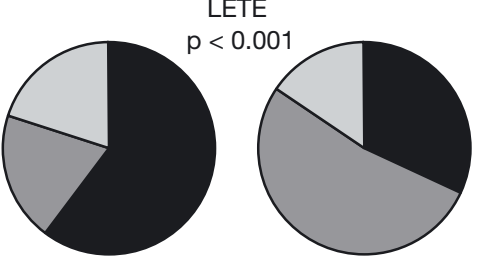

THEL

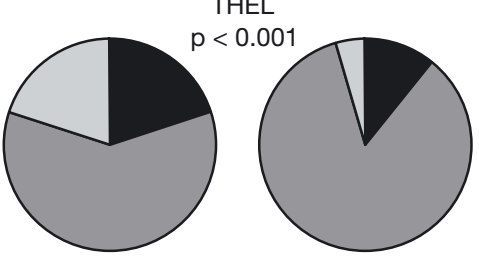

$\mathrm{TRCH}$

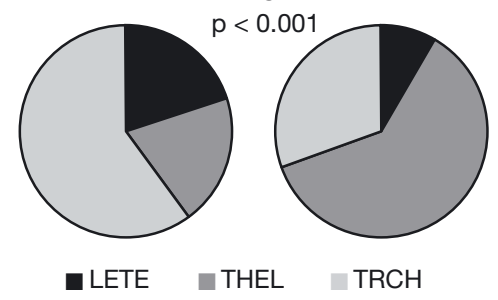

Fig. 1. Expected (based on the number of conidia in the initial inocula) and observed relative specific conidial production (based on the number of conidia per microcosm) accumulated by Day 28 for each assemblage type and dominance treatment. $\mathrm{p}$-values from $\chi^{2}$ tests performed within each dominance treatment to compare the observed and expected assemblages are given. The same pattern was observed when conidial production was expressed in terms of mass. Even: equal mix of species; LETE: Lemonniera terrestris, ARTE: Articulospora tetracladia, THEL: Tetrachaetum elegans, CLAQ: Clavariopsis aquatica, TRCH: Tricladium chaetocladium, TEMA: Tetracladium marchalianum 

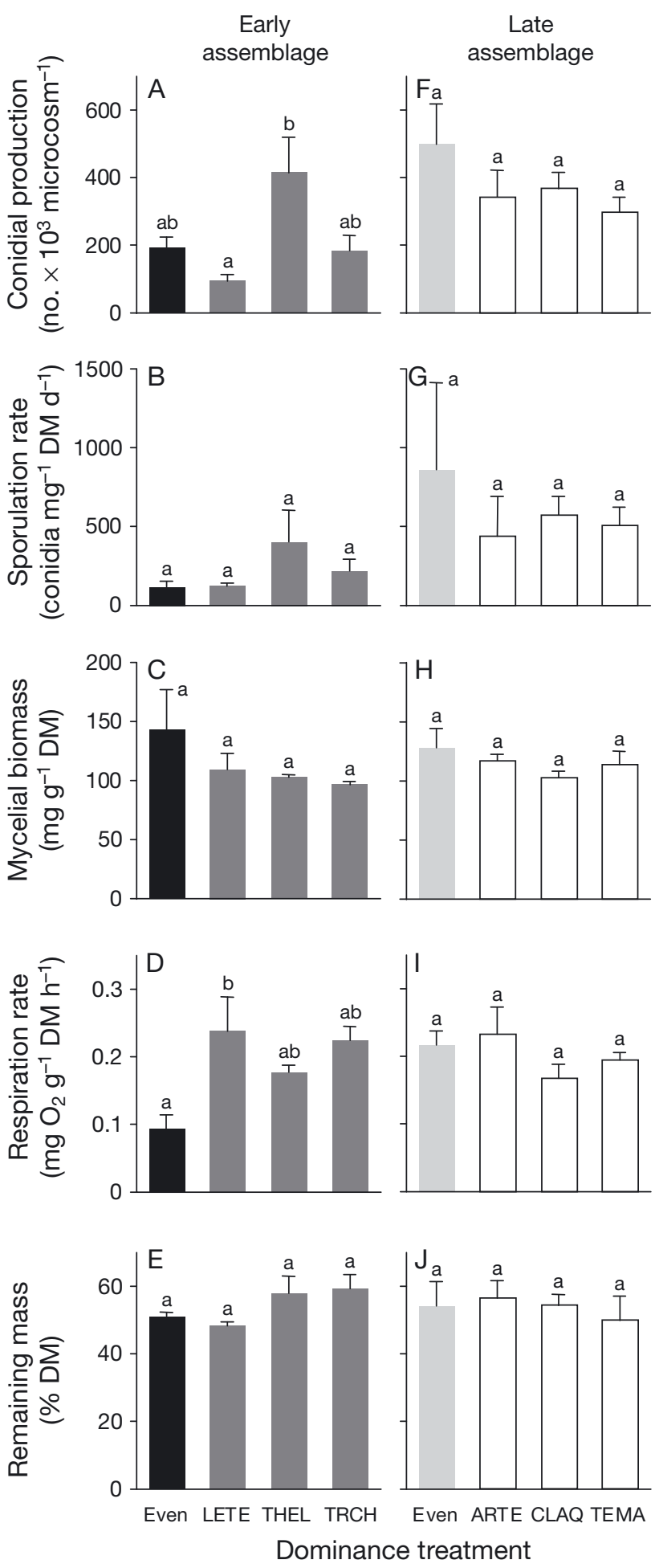

Fig. 2. Total conidial production accumulated by Day 28, and sporulation rate, mycelial biomass, respiration rate and leaf mass remaining at Day 28 for each assemblage type and dominance treatment (see Fig. 1 for definition of species abbreviations). Values are means $+1 \mathrm{SE}$. Tukey's test results are given: treatments with the same letter are not significantly different $(p>0.05)$. DM: Dry mass was related to its abundance in the inocula (linear regression, $R^{2}=0.95, p=0.023$ ) (Fig. 1). The conidial production by TRCH across treatments was related to its abundance in the inocula (linear regression, $\mathrm{R}^{2}=0.94, \mathrm{p}=0.028$ ) (Fig. 1), and TRCH (56 294 conidia microcosm ${ }^{-1}$ ) co-dominated with THEL (111901 conidia microcosm ${ }^{-1}$ ) in the TRCH treatment (Tukey's test, $\mathrm{p}=0.980$ ) (Fig. 1). LETE conidial production was not related with its initial abundance (linear regression, $\mathrm{R}^{2}<0.001, \mathrm{p}=0.973$ ) (Fig. 1), and LETE (30352 conidia microcosm ${ }^{-1}$ ) co-dominated with THEL (50 022 conidia microcosm ${ }^{-1}$ ) in the LETE treatment (Tukey's test, $\mathrm{p}=0.999$ ) (Fig. 1). Similar patterns of species abundance across treatments occurred when considering conidial production in terms of conidial mass (data not shown).

Total conidial production over the $28 \mathrm{~d}$ was significantly higher for the THEL treatment (415301 conidia microcosm ${ }^{-1}$ ) than for the LETE treatment (95 050 conidia microcosm ${ }^{-1}$ ) (Tukey's test, ANOVA, $\mathrm{p}=$ 0.040) (Fig. 2A). Sporulation rates associated with alder discs at Day 28 varied between 119 and 404 conidia $\mathrm{mg}^{-1} \mathrm{DM} \mathrm{d} \mathrm{d}^{-1}$ but were not significantly affected by dominance treatment (nested ANOVA, $\mathrm{p}=0.187$ for dominance level [even vs. uneven] and $p=0.220$ for dominance type nested within dominance level) (Fig. 2B).

The mycelial biomass on alder discs at the last day varied between 97 and $143 \mathrm{mg} \mathrm{g}^{-1} \mathrm{DM}$ but was not significantly affected by changes in assemblage type or identity of the dominant species (nested ANOVA, $p=0.088$ for dominance level and $p=0.839$ for dominance type nested within dominance level) (Fig. 2C). Respiration rates of fungi were significantly lower in the Even treatment $\left(0.09 \mathrm{mg} \mathrm{O}_{2} \mathrm{~g}^{-1} \mathrm{DM} \mathrm{h}^{-1}\right)$ than in the LETE treatment $\left(0.24 \mathrm{mg} \mathrm{O}_{2} \mathrm{~g}^{-1} \mathrm{DM} \mathrm{h}^{-1}\right.$; Tukey's test, $\mathrm{p}=0.040$ ) (Fig. 2D). The mass of alder discs remaining after $28 \mathrm{~d}$ varied between 48 and $59 \%$ and did not significantly differ among treatments (nested ANOVA, $p=0.321$ for dominance level and $p=0.089$ for dominance type nested within dominance level) (Fig. 2E).

No relationship was found between the dominance index and conidial production, mycelial biomass, $\mathrm{O}_{2}$ consumption or alder mass remaining across treatments (Pearson correlation, -0.43 [respiration rate] < $\mathrm{r}<0.57$ [total conidial production], $\mathrm{p}>0.050$ ).

\section{Late assemblages}

Late assemblages tended to be dominated by the species most represented in the inoculum $\left(\chi^{2}\right.$ tests, 
Table 1. Summary table for 2-way ANOVAs performed on total specific conidial production (numbers and mass) associated with alder leaf discs, accumulated by Day 28

\begin{tabular}{|c|c|c|c|c|c|c|c|c|c|}
\hline & \multirow{3}{*}{$\mathrm{df}$} & \multicolumn{4}{|c|}{ Early assemblage } & \multicolumn{4}{|c|}{ Late assemblage } \\
\hline & & \multicolumn{2}{|c|}{ Number } & \multicolumn{2}{|c|}{ Mass } & \multicolumn{2}{|c|}{ Number } & \multicolumn{2}{|c|}{ Mass } \\
\hline & & $F$ & $\mathrm{p}$ & $F$ & $\mathrm{p}$ & $F$ & $\mathrm{p}$ & $F$ & $\mathrm{p}$ \\
\hline Intercept & 1 & 12915.1 & 0 & 1718.9 & 0.000 & 11885.7 & 0.000 & 1548.6 & 0 \\
\hline Dominance treatment & 3 & 3.5 & 0.030 & 3.5 & 0.030 & 0.6 & 0.594 & 0.6 & 0.594 \\
\hline Sporulating species & 2 & 37.6 & $<0.001$ & 74.7 & $<0.001$ & 1.0 & 0.366 & 7.3 & 0.003 \\
\hline Dominance $\times$ Species & 6 & 3.7 & 0.010 & 3.7 & 0.010 & 3.1 & 0.022 & 3.1 & 0.022 \\
\hline Error & 24 & & & & & & & & \\
\hline
\end{tabular}

Fig. 1). In the Even treatment, all 3 species co-dominated (Fig. 1). ARTE conidial production was higher in the Even and ARTE treatments (171581 and 171402 conidia microcosm ${ }^{-1}$, respectively) than in the TEMA one (59301 conidia microcosm ${ }^{-1}$; Fisher's test, $\mathrm{p}<0.042$ ) (Fig. 1, Table 1). ARTE tended to dominate in the ARTE treatment, although differences between its conidial production (171402 conidia microcosm ${ }^{-1}$ ) and that of the second best-performing species (TEMA; 100489 conidia microcosm ${ }^{-1}$ ) were non significant (Fisher's test, $\mathrm{p}=0.107$ ) (Fig. 1, Table 1). CLAQ conidial production was related with its abundance in the inocula (linear regression, $\mathrm{R}^{2}=$ 0.97, $\mathrm{p}=0.015)$; CLAQ tended to dominate in the CLAQ treatment (203143 conidia microcosm ${ }^{-1}$ ), despite the difference from TEMA (96777 conidia microcosm ${ }^{-1}$ ) being non-significant due to high variation (Fisher's test, $\mathrm{p}=0.062$ ) (Fig. 1, Table 1). TEMA conidial production did not significantly differ among treatments (Fisher's test, $p>0.112$ ), and TEMA dominated in the TEMA treatment (Fisher's test, $\mathrm{p}<0.039$ ) (Fig. 1, Table 1). Similar patterns of species abundance across treatments occurred when considering conidial production in terms of conidial mass (data not shown).

Despite differences in specific conidial production within and among dominance treatments, the total conidial production over $28 \mathrm{~d}$ did not significantly differ among treatments (297636 to 498173 conidia microcosm ${ }^{-1}$; nested ANOVA, $p=0.105$ for dominance level [even vs uneven] and $p=0.811$ for dominance type nested within dominance level) (Fig. 2F). Sporulation rates associated with alder discs at Day 28 varied between 441 and 861 conidia $\mathrm{mg}^{-1} \mathrm{DM}$ $\mathrm{d}^{-1}$, but due to high variability did not significantly differ among treatments (nested ANOVA, $p=0.623$ for dominance level and $p=0.641$ for dominance type nested within dominance level) (Fig. 2G).

The mycelial biomass in alder discs (102 to $128 \mathrm{mg}$ $\left.\mathrm{g}^{-1} \mathrm{DM}\right)$, respiration rate of fungi ( 0.17 to $0.23 \mathrm{mg} \mathrm{O}$ $\mathrm{g}^{-1} \mathrm{DM} \mathrm{h}^{-1}$ ) and mass of alder discs remaining (50 to $56 \%$ ) at the last date were not significantly affected by dominance treatment (nested ANOVA, $p=0.199$, $\mathrm{p}=0.555$ and $\mathrm{p}=0.938$ for each dominance level, respectively; $\mathrm{p}=0.505, \mathrm{p}=0.268$ and $\mathrm{p}=0.725$ for dominance type nested within dominance level, respectively) (Fig. 2H,I,J).

The Berger-Parker dominance index was high for all treatments (0.54 to 0.62). No relationship was, however, found between the dominance index and conidial production, mycelial biomass, $\mathrm{O}_{2}$ consumption or litter-induced mass loss across treatments (Pearson correlation, 0.14 [respiration rates] $<\mathrm{r}<0.62$ [fungal biomass], $\mathrm{p}>0.050$ ).

\section{DISCUSSION}

In early assemblages, THEL became the dominant species (based on reproductive output) irrespective of its relative abundance in the initial inocula, indicating that THEL has high competitive ability and that the important factor was the initial number of THEL conidia in suspension. In contrast, TRCH and LETE were weak competitors, even when inoculated in 3-fold higher density than THEL. In a previous study (Treton et al. 2004), THEL was shown to control the growth and reproductive activity of Flagellospora curvula by delaying and inhibiting $F$. curvula germtube production and by limiting the area in which it could grow; this could also have been the case here. In late assemblages, dominance was predicted from the relative abundance of conidia in the inocula, indicating that, in some cases, species dominance is ruled by this factor. Differences between the specific relative abundance of conidia produced over the incubation time and that initially present in the inoculum might be attributed to (1) interspecific interactions and/or (2) differences in the attaching success of different conidial species due to differ- 
ences in conidial shape, size and/or length of the germ tube before appressorium formation (Dang et al. 2007). These might also explain why in some cases the structure of the conidial production associated with submerged litter does not mirror that of the conidia in stream water (Shearer \& Webster 1985, Nikolcheva et al. 2005).

In early assemblages, total conidial production and respiration rates significantly differed among treatments, which can not be attributed to a distinct identity of the dominant species given that THEL dominated in all 4 assemblages. These differences can, however, be partially attributed to differences in the density of the dominant species. For instance, total conidial production was higher in the THEL treatment, in which this species was inoculated at the highest density and where its conidial production over the incubation period was the highest, than in the LETE treatment, in which THEL was inoculated at lower density and where its conidial production over the incubation period was the lowest. In contrast, late assemblages did not significantly differ in any of the fungal variables assessed (reproductive activity, fungal biomass and respiration), even though they were dominated by distinct species.

Note, however, that dominance was assessed based on specific conidial density (reproductive output), which might not necessarily reflect specific mycelial biomass in the leaf litter. Once established on the litter, interactions among fungal species take place at the mycelial level, which makes the specific mycelial biomass and its relative contribution to total fungal biomass more relevant than specific conidial density. Therefore, if specific mycelial biomass does not relate to specific conidial production, studies of the fungal diversity and function relationship might be biased. Current standard methods for the determination of fungal biomass, e.g. ergosterol solidphase extraction (Graça et al. 2005) or microwaveassisted ergosterol extraction (Young 1995), do not facilitate the assessment of species contributions to total fungal biomass. The determination of specific fungal biomass using species-specific antibodies (Bermingham et al. 1997) is not a practical alternative because it is highly time consuming and expensive. Identification of species contributions to total fungal biomass in microcosm experiments could, however, be achieved with molecular techniques (e.g. realtime PCR) (Krauss et al. 2011). Also, the substitution of the conidial suspension with sterile nutrient solution every $3 \mathrm{~d}$ might have affected the assemblage structure. In streams, the unidirectional flow of water washes the conidia away from the litter at the same time that it brings conidia from upstream reaches, so there are always suspended conidia that may colonize the leaf litter and influence the development of the community.

Despite the differences in dominance/evenness and/or identity of the dominant species among assemblages, there were no significant differences in litter-mass loss, which seems to indicate functional redundancy among aquatic hyphomycete assemblages, as suggested by some field experiments (Bärlocher \& Graça 2002, Pascoal et al. 2005, Ferreira et al. 2006b). Still, because the identity of the dominant species changed in late assemblages, and the various species have been reported to differ in their abilities to decompose litter (Suberkropp \& Klug 1980, Arsuffi \& Suberkropp 1984, 1985, Butler \& Suberkropp 1986), functional redundancy was not expected.

A few studies have to date addressed the relationship between community dominance (or its complementary notion of evenness) and ecosystem processes (in contrast with the vast literature on the relationship between species richness and ecosystem functions), but the results are still somewhat conflicting, although dominant species identity plays an important role. For instance, in an old-field ecosystem, total plant biomass increased with increasing evenness, independently of the identity of the dominant species, while the relationship between aboveground biomass and species evenness depended on the identity of the dominant species (Wilsey \& Potvin 2000). The identity of the dominant litter species influenced the decomposition of litter mixtures in a peatland (Ward et al. 2010). In stream ecosystems, Dangles \& Malmqvist (2004) reported a strong positive relationship between shredder dominance and litter decomposition, with a strong effect of dominant species identity, and McKie et al. (2008) found that leaf-processing efficiency in some invertebrate assemblages was affected by the identity of the dominant species. Decomposition of submerged litter mixtures also seems to be affected by the relative abundance of component species (Gonçalves \& Canhoto 2009, Swan et al. 2009). In our case, the absence of a relationship between community dominance or identity of the dominant species and community performance or litter-mass loss indicates that assemblages, even those composed of a low number of species, have the capacity to buffer changes in species dominance in an important ecosystem process.

Changes in the identity of the dominant species in aquatic hyphomycete assemblages might nevertheless indirectly influence litter decomposition through a bottom-up effect. Aquatic detritivores have been 
shown to have feeding preferences for litter colonized by certain fungal species (Bärlocher \& Kendrick 1973, Arsuffi \& Suberkropp 1984, 1985, Butler \& Suberkropp 1986, but see Chung \& Suberkropp 2009), which translates into differences in consumption rate, growth rate and survivorship (Arsuffi \& Suberkropp 1986). Leaf litter colonized by more palatable fungal species is therefore expected to be preferentially consumed by detritivores and consequently to decompose faster. This, however, depends on the detritivore being a key species in litter processing in the system and on its ability to distinguish among fungal species.

Aquatic hyphomycetes have the capacity to retrieve nutrients from both the organic substrate and the water column (Suberkropp 1998), and it is well known that changes in dissolved nutrient concentration induce shifts in fungal species abundance (Dang et al. 2005, Artigas et al. 2008, Ferreira \& Chauvet 2011). Therefore, distinct dominance patterns could have been obtained if lower nutrient concentrations had been used in this study. Nevertheless, future increases in temperature (IPCC 2007) might lead to increases in evaporation and evapotranspiration and increases in water extraction to satisfy the needs of a growing human population (Murdoch et al. 2000), which, together with increases in nutrients loads from agricultural activities and urban and industrial effluents, will most likely aggravate the trophic state of freshwaters. Such a scenario might favor highdemanding species or species with low enzymatic capabilities.

The effect of changes in fungal community structure, and species dominance, on litter decomposition might be stronger if low-quality litter is considered. Alder is a common riparian tree species and contributes much to the instream organic matter pool (Molinero \& Pozo 2006), being preferably colonized and decomposed by aquatic communities than other more recalcitrant litter species (Gessner \& Chauvet 1994, Canhoto \& Graça 1995, 1996). However, the contribution of this soft, nutrient-rich litter to the autumn litter bulk might become reduced in many streams as a consequence of the infestation of alder trees by the fungus Phytophthora alni, which causes rapid death of infected trees and is presently widespread in many European countries (Brasier et al. 2004, Thoirain et al. 2007). This problem might become even more serious under global warming because the sporulation by $P$. alni increases with temperature (Chandelier et al. 2006). Also, litter quality (nitrogen concentration) is expected to decrease under future atmospheric $\mathrm{CO}_{2}$ enrichment
(Cotrufo et al. 1998). Under these scenarios, aquatic food webs might have to rely more on poorer quality litter, whose decomposition will be more demanding in terms of enzymatic capabilities. This might favor the dominance of aquatic hyphomycete species which are usually poor competitors on nutrient-rich litter. The identity of the dominant fungal species on these poorer quality substrates might become more important for determining the feeding activities of invertebrates. More investigation of the relationship between fungi and invertebrates under changing environments is necessary to allow the identification of cascading effects on aquatic food webs.

Acknowledgements. We thank Julien Cornut and Michael Danger for isolation of aquatic hyphomycete species, and Sylvain Lamothe and Didier Lambrigot for providing technical help. Comments provided by 3 anonymous referees on an early version of the manuscript were most appreciated. Financial support granted by the FEDER European funds through the Program Operational Factors of Competitiveness (COMPETE) and national funds through the Portuguese Science Foundation (FCT; program POPH/FSE, reference SFRH/ BPD/34368/2006) to V.F. and by the CNRS (National Center for Scientific Research) to E.C., as well as the Pessoa exchange program between Portugal and France (PHC 22808TB) from the French Ministry of Foreign and European Affairs, are gratefully acknowledged.

\section{LITERATURE CITED}

Arsuffi TL, Suberkropp K (1984) Leaf processing capabilities of aquatic hyphomycetes: interspecific differences and influence on shredder feeding preferences. Oikos 42: $144-154$

Arsuffi TL, Suberkropp K (1985) Selective feeding by stream caddisfly (Trichoptera) detritivores on leaves with fungal-colonized patches. Oikos 45:50-58

Arsuffi TL, Suberkropp K (1986) Growth of two stream caddisflies (Trichoptera) on leaves colonized by different fungal species. J N Am Benthol Soc 5:297-305

> Artigas J, Romaní AM, Sabater S (2008) Affect of nutrients on the sporulation and diversity of aquatic hyphomycetes on submerged substrata in a Mediterranean stream. Aquat Bot 88:32-38

Bärlocher F (1985) The role of fungi in the nutrition of stream invertebrates. Bot J Linn Soc 91:83-94

Bärlocher F, Corkum M (2003) Nutrient enrichment overwhelms diversity effects in leaf decomposition by stream fungi. Oikos 101:247-252

Bärlocher F, Graça MAS (2002) Exotic riparian vegetation lowers fungal diversity but not leaf decomposition in Portuguese streams. Freshw Biol 47:1123-1135

Bärlocher F, Kendrick B (1973) Fungi and food preferences of Gammarus pseudolimnaeus. Arch Hydrobiol 72: 501-516

Bärlocher F, Schweizer M (1983) Effects of leaf size and decay rate on colonization by aquatic hyphomycetes. Oikos 41:205-210

Baudoin JM, Guérold F, Felten V, Chauvet E, Wagner P, Rousselle P (2008) Elevated aluminium concentration in 
acidified headwater streams lowers aquatic hyphomycete diversity and impairs leaf-litter breakdown. Microb Ecol 56:260-269

Berger WH, Parker FL (1970) Diversity of planktonic foraminifera in deep-sea sediments. Science 168:1345-1347

Bermingham S, Maltby L, Dewey FM (1997) Use of immunoassays for the study of natural assemblages of aquatic hyphomycetes. Microb Ecol 33:223-229

Brasier CM, Kirk SA, Delcan J, Cooke DEL, Jung T, Veld WAMI (2004) Phytophthora alni sp. nov. and its variants: designation of emerging heteroploid hybrid pathogens spreading on Alnus trees. Mycol Res 108:1172-1184

> Butler SK, Suberkropp K (1986) Aquatic hyphomycetes on oak leaves: comparison of growth, degradation and palatability. Mycologia 78:922-928

Canhoto C, Graça MAS (1995) Food value of introduced eucalypt leaves for a Mediterranean stream detritivore: Tipula lateralis. Freshw Biol 34:209-214

Canhoto C, Graça MAS (1996) Decomposition of Eucalyptus globulus leaves and three native leaf species (Alnus glutinosa, Castanea sativa and Quercus faginea) in a Portuguese low order stream. Hydrobiologia 333:79-85

> Castela J, Ferreira V, Graça MAS (2008) Evaluation of stream ecological integrity using litter decomposition and benthic invertebrates. Environ Pollut 153:440-449

> Chadwick MA, Dobberfuhl DR, Benke AC, Huryn AD, Suberkropp K, Thiele JE (2006) Urbanization affects stream ecosystem function by altering hydrology, chemistry, and biotic richness. Ecol Appl 16:1796-1807

> Chamier AC, Dixon PA, Archer SA (1984) The spatial distribution of fungi on decomposing alder leaves in a freshwater stream. Oecologia 64:92-103

> Chandelier A, Abras S, Laurent F, Debruxelles N, Cavelier $M$ (2006) Effect of temperature and bacteria on sporulation of Phytophthora alni in river water. Commun Agric Appl Biol Sci 71:873-880

> Chauvet E, Suberkropp K (1998) Temperature and sporulation of aquatic hyphomycetes. Appl Environ Microbiol 64:1522-1525

> Chung N, Suberkropp K (2009) Effects of aquatic fungi on feeding preferences and bioenergetics of Pycnopsyche gentilis (Trichoptera: Limnephilidae). Hydrobiologia 630: 257-269

Cotrufo MF, Ineson P, Scott A (1998) Elevated $\mathrm{CO}_{2}$ reduces the nitrogen concentration of plant tissues. Global Change Biol 4:43-54

> Dang CK, Chauvet E, Gessner MO (2005) Magnitude and variability of process rates in fungal diversity-litter decomposition relationships. Ecol Lett 8:1129-1137

> Dang CK, Gessner MO, Chauvet E (2007) Influence of conidial traits and leaf structure on attachment success of aquatic hyphomycetes on leaf litter. Mycologia 99:24-32

> Dang CK, Schindler M, Chauvet E, Gessner MO (2009) Temperature oscillation coupled with fungal community shifts can modulate warming effects on litter decomposition. Ecology (USA) 90:122-131

> Dangles O, Malmqvist B (2004) Species richness-decomposition relationships depend on species dominance. Ecol Lett 7:395-402

> deKozlowski SJ, Bunting DL (1981) A laboratory study on the thermal tolerance of four southeastern stream insect species (Trichoptera, Ephemeroptera). Hydrobiologia 79: 141-145

> Duarte S, Pascoal C, Cássio F, Bärlocher F (2006) Aquatic hyphomycete diversity and identity affect leaf litter decomposition in microcosms. Oecologia 147:658-666

Eaton JG, Scheller RM (1996) Effects of climate warming on fish thermal habitat in streams on the United States. Limnol Oceanogr 41:1109-1115

- Ellison AM, Bank MS, Clinton BD, Colburn EA and others (2005) Loss of foundation species: consequences for the structure and dynamics of forested ecosystems. Front Ecol Environ 3:479-486

Ferreira V, Chauvet E (2011) Synergistic effects of water temperature and dissolved nutrients on litter decomposition and associated fungi. Global Change Biol 17: 551-564

> Ferreira V, Elosegi A, Gulis V, Pozo J, Graça MAS (2006a) Eucalyptus plantations affect fungal communities associated with leaf litter decomposition in Iberian streams. Arch Hydrobiol 166:467-490

> Ferreira V, Gulis V, Graça MAS (2006b) Whole-stream nitrate addition affects litter decomposition and associated fungi but not invertebrates. Oecologia 149:718-729

> Fisher SG, Likens GE (1973) Energy flow in Bear Brook, New Hampshire: an integrative approach to stream ecosystem metabolism. Ecol Monogr 43:421-439

> Gessner MO, Chauvet E (1993) Ergosterol-to-biomass conversion factors for aquatic hyphomycetes. Appl Environ Microbiol 59:502-507

Gessner MO, Chauvet E (1994) Importance of stream microfungi in controlling breakdown rates of leaf litter. Ecology (USA) 75:1807-1817

Gessner MO, Thomas M, Jean-Louis AM, Chauvet E (1993) Stable successional patterns of aquatic hyphomycetes on leaves decaying in a summer cool stream. Mycol Res 97: $163-172$

Gessner MO, Robinson CT, Ward JV (1998) Leaf breakdown in streams of an alpine glacial floodplain: dynamics of fungi and nutrients. J N Am Benthol Soc 17:403-419

Gonçalves AL, Canhoto C (2009) Decomposition of eucalyptus and alder mixtures: responses to variation in evenness. Fundam Appl Limnol Arch Hydrobiol 173:293-303

Graça MAS, Bärlocher F, Gessner MO (2005) Methods to study litter decomposition. A practical guide. Springer, Dordrecht

> Gulis V, Suberkropp K (2003) Effect of inorganic nutrients on relative contribution of fungi and bacteria to carbon flow from submerged decomposing leaf litter. Microb Ecol 45:11-19

> Hieber M, Gessner MO (2002) Contribution of stream detritivores, fungi, and bacteria to leaf breakdown based on biomass estimates. Ecology (USA) 83:1026-1038

Hillebrand H, Bennett DM, Cadotte MW (2008) Consequences of dominance: a review of evenness effects on local and regional ecosystem processes. Ecology (USA) 89:1510-1520

IPCC (Intergovernmental Panel on Climate Change) (2007) Climate change 2007: The physical science basis. Solomon S, Qin D, Manning M, Chen Z and others (eds) Contribution of Working Group I to the Fourth Assessment Report of the Intergovernmental Panel on Climate Change. Cambridge University Press, Cambridge

Krauss GJ, Solé M, Krauss G, Schlosser D, Wesenberg D, Bärlocher F (2011) Fungi in freshwaters: ecology, physiology and biochemical potential. FEMS Microbiol Rev 35:620-651

$>$ Lecerf A, Patfield D, Boiché A, Riipinen MP, Chauvet E, Dobson M (2007) Stream ecosystems respond to riparian invasion by Japanese knotweed (Fallopia japonica). Can 
J Fish Aquat Sci 64:1273-1283

McKie BG, Woodward G, Hladyz S, Nistorescu M and others (2008) Ecosystem functioning in stream assemblages from different regions: contrasting responses to variation in detritivore richness, evenness and density. J Anim Ecol 77:495-504

MEA (Millennium Ecosystem Assessment) (2005) Ecosystems and human well-being: synthesis. Island Press, Washington, DC

> Molinero J, Pozo J (2006) Organic matter, nitrogen and phosphorus fluxes associated with leaf litter in two small streams with different riparian vegetation: a budget approach. Arch Hydrobiol 166:363-385

Mulholland PJ, Fellows CS, Tank JL, Grimm NB and others (2001) Inter-biome comparison of factors controlling stream metabolism. Freshw Biol 46:1503-1517

Murdoch PS, Baron JS, Miller TL (2000) Potential effects of climate change on surface-water quality in North America. J Am Water Resour Assoc 36:347-366

> Nikolcheva LG, Bärlocher F (2005) Seasonal and substrate preferences of fungi colonizing leaves in streams: traditional versus molecular evidence. Environ Microbiol 7: 270-280

Nikolcheva LG, Cockshutt AM, Bärlocher F (2003) Determining diversity of freshwater fungi on decaying leaves: comparison of traditional and molecular approaches. Appl Environ Microbiol 69:2548-2554

Nikolcheva LG, Bourque T, Bärlocher F (2005) Fungal diversity during initial stages of leaf decomposition in a stream. Mycol Res 109:246-253

Pascoal C, Cássio F (2004) Contribution of fungi and bacteria to leaf litter decomposition in a polluted river. Appl Environ Microbiol 70:5266-5273

Pascoal C, Cássio F, Marvanová L (2005) Anthropogenic stress may affect aquatic hyphomycete diversity more than leaf decomposition in a low-order stream. Arch Hydrobiol 162:481-496

Shearer CA, Webster J (1985) Aquatic hyphomycete communities in the River Teign. III. Comparison of sampling techniques. Trans Br Mycol Soc 84:509-518

Smith MD, Knapp AK (2003) Dominant species maintain ecosystem function with non-random species loss. Ecol Lett 6:509-517

Suberkropp K (1991) Relationships between growth and sporulation of aquatic hyphomycetes on decomposing litter. Mycol Res 95:843-850

Editorial responsibility: Tom Battin,

Vienna, Austria
Suberkropp K (1998) Effect of dissolved nutrients on two aquatic hyphomycetes growing on leaf litter. Mycol Res 102:998-1002

Suberkropp K (2001) Fungal growth, production, and sporulation during leaf decomposition in two streams. Appl Environ Microbiol 67:5063-5068

Suberkropp K, Arsuffi TL (1984) Degradation, growth, and changes in palatability of leaves colonized by six aquatic hyphomycete species. Mycologia 76:398-407

Suberkropp K, Chauvet E (1995) Regulation of leaf breakdown by fungi in streams: influences of water chemistry. Ecology (USA) 76:1433-1445

Suberkropp K, Klug MJ (1980) The maceration of deciduous leaf litter by aquatic hyphomycetes. Can J Bot 58: 1025-1031

Suberkropp K, Arsuffi TL, Anderson JP (1983) Comparison of degradative ability, enzymatic activity, and palatability of aquatic hyphomycetes grown on leaf litter. Appl Environ Microbiol 46:237-244

Swan CM, Gluth MA, Horne CL (2009) Leaf litter species evenness influences nonadditive breakdown in a headwater stream. Ecology (USA) 90:1650-1658

> Thoirain B, Husson C, Marçais B (2007) Risk factors for the Phytophthora-induced decline of alder in northeastern France. Phytopathology 97:99-105

- Treton C, Chauvet E, Charcosset JY (2004) Competitive interaction between two aquatic hyphomycete species and increase in litter breakdown. Microb Ecol 48: 439-446

> Vannote RL, Minshall GW, Cummins KW, Sedell JR, Cushing CE (1980) The river continuum concept. Can J Fish Aquat Sci 37:130-137

> Ward SE, Ostle NJ, McNamara NP, Bardgett RD (2010) Litter evenness influences short-term peatland decomposition processes. Oecologia 164:511-520

- Wilsey BJ, Potvin C (2000) Biodiversity and ecosystem functioning: importance of species evenness in an old field. Ecology 81:887-892

Young JC (1995) Microwave-assisted extraction of the fungal metabolite ergosterol and total fatty acids. J Agric Food Chem 43:2904-2910

Zar JH (1996) Biostatistical analysis, 3rd edn. Prentice-Hall International, Englewood Cliffs, NJ

Zemek J, Marvanová L, Kuniak L, Kadlecíková B (1985) Hydrolytic enzymes in aquatic hyphomycetes. Folia Microbiol 30:363-371

Submitted: August 23, 2011; Accepted: January 18, 2012

Proofs received from author(s): March 5, 2012 